\title{
Study of Universal Thermal Comfort Index in Hosing Estate Public Space in Bangkok, Thailand
}

Pitiwat Wattanachai ${ }^{1}$, Chawanat Sundaranaga ${ }^{2}$, Thidarat Kridakorn Na Ayutthaya ${ }^{3,4}$, Non Phichetkunbodee ${ }^{4}$, Damrongsak Rinchumphu ${ }^{1,45^{*}}$

\author{
${ }^{1}$ Department of Civil Engineering, Faculty of Engineering, Chiang Mai University, Thailand \\ ${ }^{2}$ First Estate and Consultants Company Limited, Thailand \\ 3Department of Environmental Engineering, Faculty of Engineering, Chiang Mai University, Thailand \\ ${ }^{4}$ City Research and Development Center, Faculty of Engineering, Chiang Mai University, Thailand \\ ${ }^{5}$ Center of Excellence for Natural Disaster Management (CENDIM), Chiang Mai University, Thailand
}

*damrongsak.r@cmu.ac.th

\begin{abstract}
A lower external temperature increases comfort and reduces the chance of heat stress; it can be impacted by the density of the urban area, and this is an important issue for the residents in housing estate developments. Therefore, to sustainably reduce this issue, the external temperature is important to manage for urban public spaces' development. This article reports the results of studies on increasing thermal comfort in public areas by adding different types of shading into computer programs, Rhinoceros and Grasshopper, to calculate the Universal Thermal Comfort Index (UTCI). Increasing the outdoor comfort can be done by adding shaded areas via large trees that can result in thermal reduction and humidity increase, but they do not obstruct air circulation. The result can be used as a guideline for the design of public spaces in housing estates to meet the outdoor comfort efficiently and support the users' expectations.
\end{abstract}

Keywords: Outdoor thermal comfort, Universal Thermal Comfort Index, Computer Simulation, Hosing estate, Public park 


\section{INTRODUCTION}

The World's temperature is starting to increase due to climate change, which is especially important in cities with many buildings. As a result, many residents in urban areas are impacted by heat stress (Li et al., 2011). To prevent the occurrence of heat stress, outdoor comfort should be considered in the design and development of housing estates by providing appropriate public space, in the form of gardens or parks (Choruengwiwat et al., 2019; Srivanit and Jareemit, 2020). Outdoor comfort is part of thermal comfort, and it is the extent of the condition where the air temperature, relative humidity, and wind speed are suitable to make the human body feel comfortable - not too hot or too cold (Nugroho et al., 2020). The human body can be compared to an internal combustion engine, it must have heat transfer otherwise it will result in uncomfortable feelings (Peccolo, 1962; Wang et al., 2004).

Outdoor thermal comfort is related to three key variables. Air temperature (Ta) is the first thermal comfort variable, which can change due to the season. The thermal comfort boundary of Thai people is between $25.6-31.5^{\circ} \mathrm{C}$ (Jitkhajornwanich, 2007; Srivanit \& Jareemit, 2020). Next, relative humidity ( $\mathrm{Rh}$ ) is another variable for thermal comfort. If the relative humidity is too high, sweat does not evaporate easily, causing hot and uncomfortable feelings. When the relative humidity is too low, sweat evaporates easily irritating the skin and nose. Approximately, a suitable relative humidity is between 62.2-90.0\% (Jitkhajornwanich, 2007). The air velocity (Va) has a convection ability that can affect humans by reducing the body temperature. If the air velocity is too low, it will not take heat from the body, causing a sultry and hot feeling. While if the air velocity is too high, it will take too much heat from the body causing a cold feeling. An air velocity that creates thermal comfort is between $1.0-2.0 \mathrm{~m} / \mathrm{s}$ (Thongsri et al., 2006). Finally, solar radiation $(\mathrm{Sr})$ is electromagnetic waves that radiate from the sun. It enters through the Earth's atmosphere and the Earth's atmosphere and surface absorbs about $65 \%$, converted into heat energy, causing the temperature of the Earth's atmosphere and surface to rise (Choruengwiwat et al., 2019). Therefore, the influences can be controlled by space designing, such as tree planting for creating the shadows or the cover way construction which can also create the shades. However, the effect of the trees results in a different moisturizing and shady atmosphere than the cover way (Abdi et al., 2020; Hsieh et al., 2018).

Therefore, one of the outdoor thermal comfort indicators that are key in several research articles is the Universal Thermal Climate Index (UTCI) (Silva
\& Hirashima, 2021; Wang \& Yi, 2021), which focuses on the presentation of the environment's temperature in a balanced state and how humans can feel at that time, but excludes personal details, and it is based on meteorological data (Blazejczyk et al., 2011; Bröde et al., 2013). However, personal details are included in the human sense for the universal environment. As an indicator, the UTCI can be measured as a feeling level, which is something that a person perceives from their skin (Bröde et al., 2011). Although UTCI has used a few variables, it is suitable for situations with variable measurement limitations. In terms of reliability, there has been considered by many research articles/journals, which have chosen UTCI as suitable for international presentation, and this has proven that UTCI is internationally reliable (Fahmy and Elwy, 2016; Havenith et al., 2011; Milosevic et al., 2017).

Outdoor well-being is very important in the grand real estate designing and developing process since it is a support in having a convenient outside lifestyle for the residencies. Moreover, it helps provide social interaction and create a way to have health care activities. Therefore, to have a rapid analysis, the study of Rakha (2015) suggested the Rhinoceros and Grasshopper Programs as they are effective programs for simulation. For more illustration, the Rhinoceros Program is the application for 3 dimension work designing which is outstanding in the parametric model and NURBS. After that, the add-on program or Grasshopper which is equipped with sets of tools that is capable in data analysis and engineering calculation such as this article's simulation that has used the toolsets named Ladybug and Honeybee for calculating the result of the UTCI as per the above mentioned.

According to a study of shaded areas, adding appropriate areas of shade affects thermal comfort, which encourages the use of public areas, and this will be beneficial to the health of the residents. To be suitable to specify design details and reduce future problems, this study has evaluated the effect of shade on outdoor conditions by using two computer programs, Rhinoceros and Grasshopper, which have been used widely in previous publications in a wide range of international academic journals (Naboni et al., 2017; Nakano et al., 2015; Rakha \& Reinhart, 2012), and this could be used to encourage design that is more environmentally friendly. The paper is structured in three sections: (1) methodology; (2) results and discussion; and (3) conclusions.

\section{MATERIAL AND METHODS}

\subsection{Study's Variables}

Several variables are required to calculate the Universal Thermal Climate Index (UTCI), as shown 
Table 1 Variables used in this study.

\begin{tabular}{|c|c|c|c|c|}
\hline No. & Variable list & Independent variable & Controlled variable & Variable description \\
\hline 1 & Air temperature: Ta & & $\checkmark$ & \multirow{5}{*}{ Weather data } \\
\hline 2 & Relative humidity: Rh & & $\checkmark$ & \\
\hline 3 & Wind velocity: Va & & $\checkmark$ & \\
\hline 4 & Solar radiation: $\mathrm{Sr}$ & & $\checkmark$ & \\
\hline 5 & Simulation Date-time & & $\checkmark$ & \\
\hline 6 & Building model & & $\checkmark$ & \multirow{3}{*}{ Physical data } \\
\hline 7 & Tree model & $\checkmark$ & & \\
\hline 8 & Cover way model & $\checkmark$ & & \\
\hline
\end{tabular}

According to the above Table 1, the variables that are relevant to the value of well-being have been divided into 2 groups which are controlled variables that must be supervised to be in the same condition in every situation (variables No. 1-6) and independent variable to study the differences of tree model and cover way model designs. Additionally, this research has used the stable secondary data as the managing variables and used the tree model and cover way model as the unrestrained variables, to study the changes and the effects of the differences.

\subsection{Outdoor Comfort Simulation}

The outdoor comfort simulation consists of the tools-used date-time setting physical models and processing from the creation of processing units, as in the description in Figure 1. This is included as an implementation methodology, according to the educational framework.

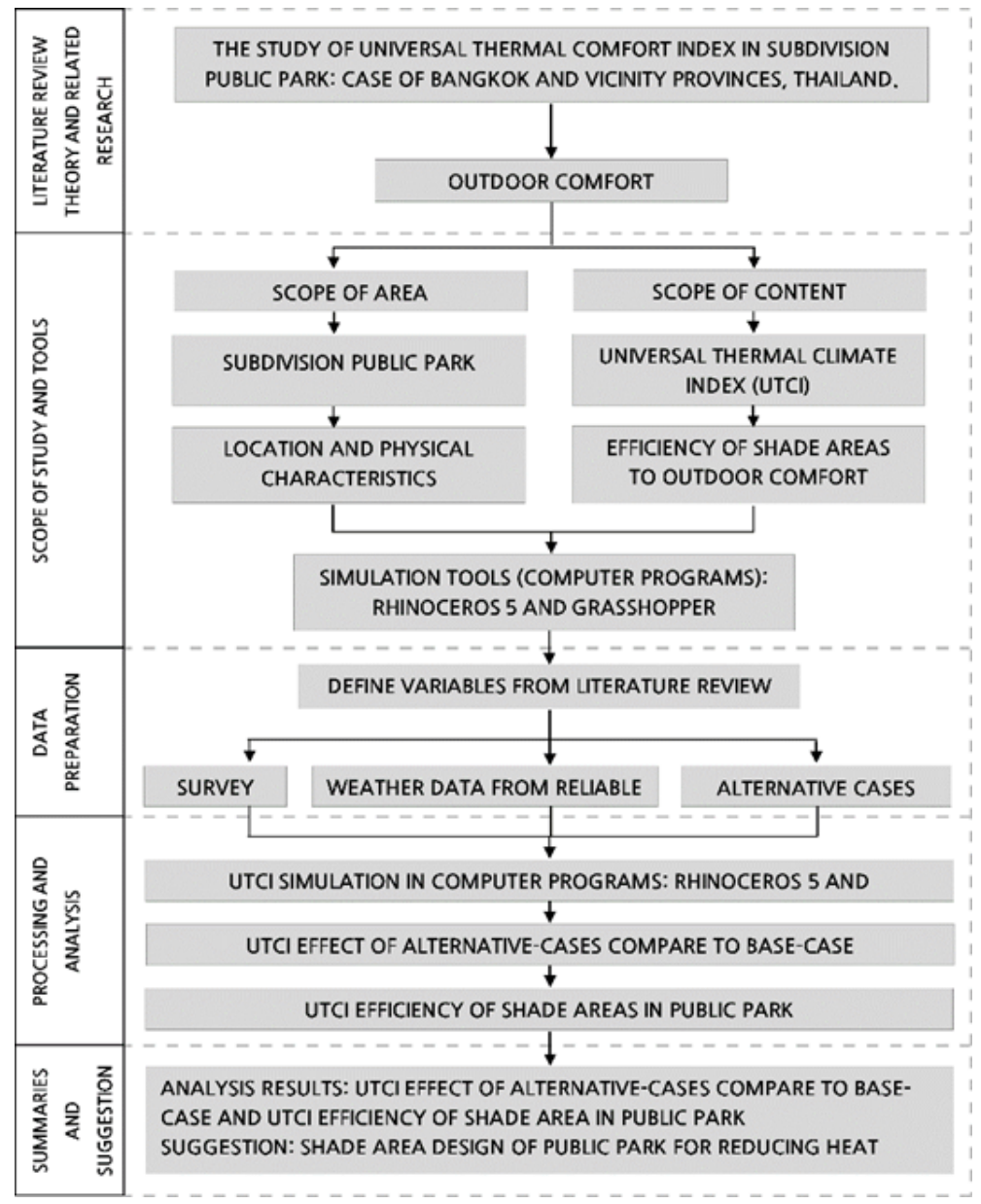

Figure 1: Method of study, according to the research framework. 
Fig. 1 describes the study processes which are split into 5 major tasks which are (1) The works of literature and related researches review is the step for studying and collecting the researches that have mentioned the outdoor comfort, (2) The step of research tools study which has been studied during the literature review since the document exploration was separated into 2 parts as the study area tools for gaining the physical data of the space and the content data for the UTCI value calculation. The study was resulted in finding the most proper tools which have been the Rhinoceros and Grasshopper, (3) The third step is the data preparation for the simulation. For more description, the inputs are both from the field survey figures and the secondary data to create an appropriate alternative, (4) Next step is to simulate by applying the Rhinoceros and Grasshopper Programs to compare the base-case with the alternative, and (5) The final step is the study summary.

\subsection{Study Area}

This study selected a public park in a housing estate in the Bangkok area, which is located at latitude 14.012129, longitude 100.681005, and with an area of $31,200 \mathrm{~m} 2$, as shown in Fig. 2. The hottest date of the year was chosen as a simulation date, and the periods for the simulation were 9:00-11:00 (representing the morning period), 13:00-15:00 (representing the maximum solar radiation period), and 16:00-18:00 (representing the full day temperature accumulation). Therefore, this article has 29 April as the simulation data, which was retrieved from weather data files called STAT and EPW, which can be downloaded from energyplus.net/weather, using the Rhinoceros and Grasshopper software.

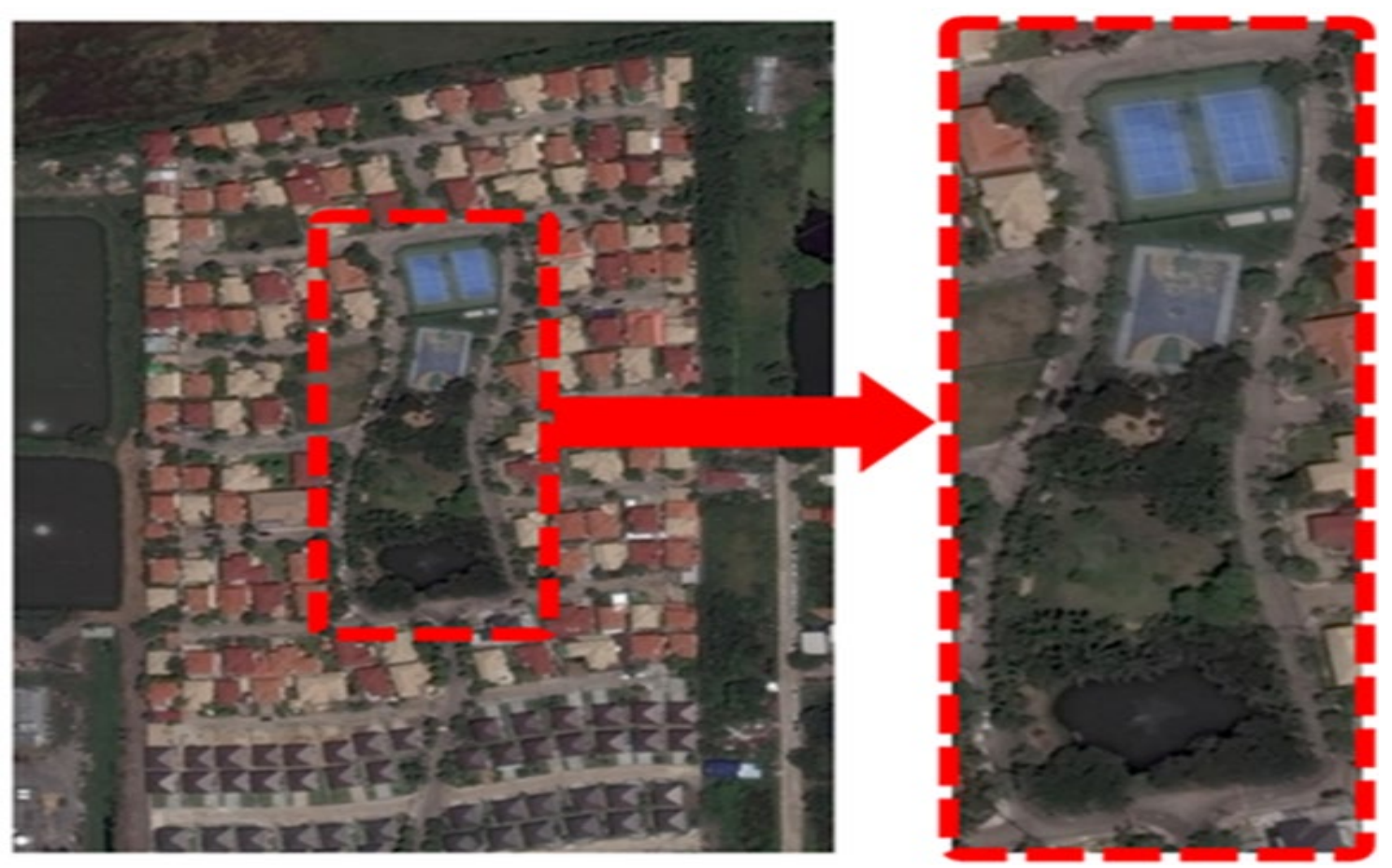

Figure 2: Public park in an urban housing estate in Bangkok.

The hottest date of the year was chosen as a simulation date, and the periods for the simulation were 9:00-11:00 (representing the morning period), 13:00-15:00 (representing the maximum solar radiation period), and 16:00-18:00 (representing the full day temperature accumulation). Therefore, this article has 29 April as the simulation data, which was retrieved from weather data files called STAT and EPW, which can be downloaded from energyplus.net/weather, using the Rhinoceros and Grasshopper software.

\subsection{Rhinoceros and Grasshopper}

Rhinoceros is a 3D computer-aided design (CAD) program that focuses on parametric modeling and NURBs ability, which can send the 3D model's data for engineering calculation and analysis in Grasshopper. Grasshopper is a visual programming language and environment, which runs within Rhinoceros, and there are many plugins in Grasshopper, such as Ladybug, Honeybee, Butterfly, and Dragonfly. Grasshopper, when using components of the plugin Ladybug, can do UTCI calculations for Rhinoceros 3D models (Roudsari \& Pak, 2013). 


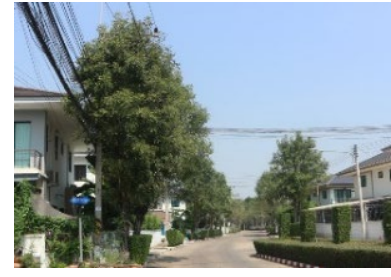

Columnar

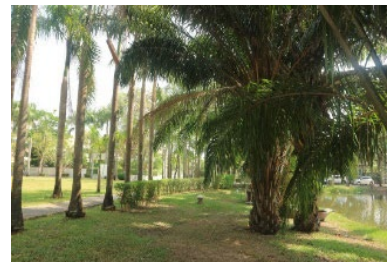

Fountain
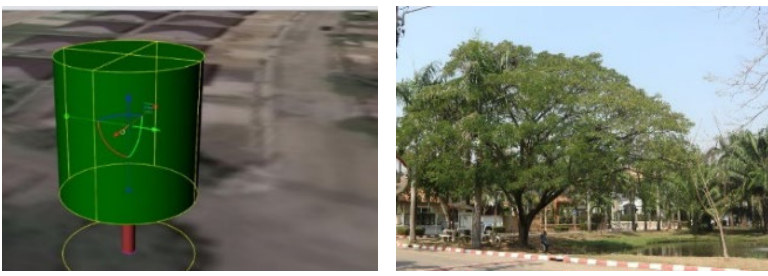

Spreading
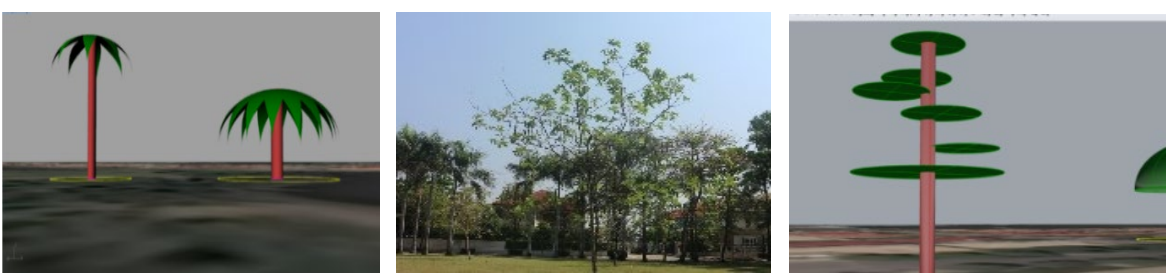

Wide fountain

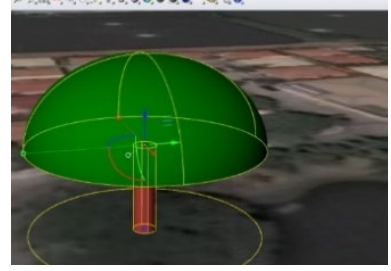

Figure 3: Tree canopies and tree canopy models used in this study, (left) natural form and (right) computer-modeled form.

The more complicated the surface, the more time that will be needed for the simulation processing. The computer models are formed by simple shapes, such as box and pyramid shapes, to represent the natural shape of the trees (Reinhart et al., 2013), and the shapes of each tree used in this research are presented in Figure 3. The weather data was downloaded from the EnergyPlus website, and the details are shown in Figure 4.

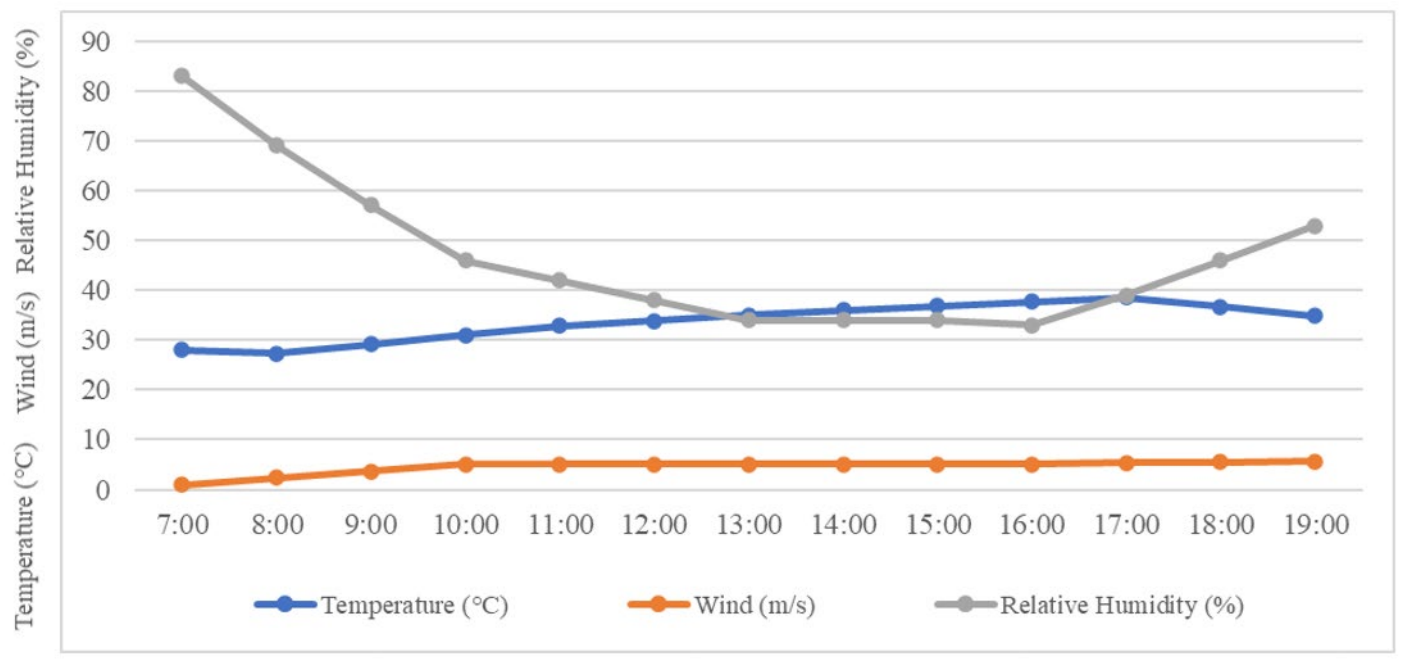

Figure 4: Weather data for a study date.

Grasshopper is a visual programming language (VPL), so the method to create a suite for processing can be done by dragging and dropping the required components into the canvas. In this study, the important components that were used in the UTCI simulation processing were obtained from the Ladybug plugin, as shown in Figure 5. 


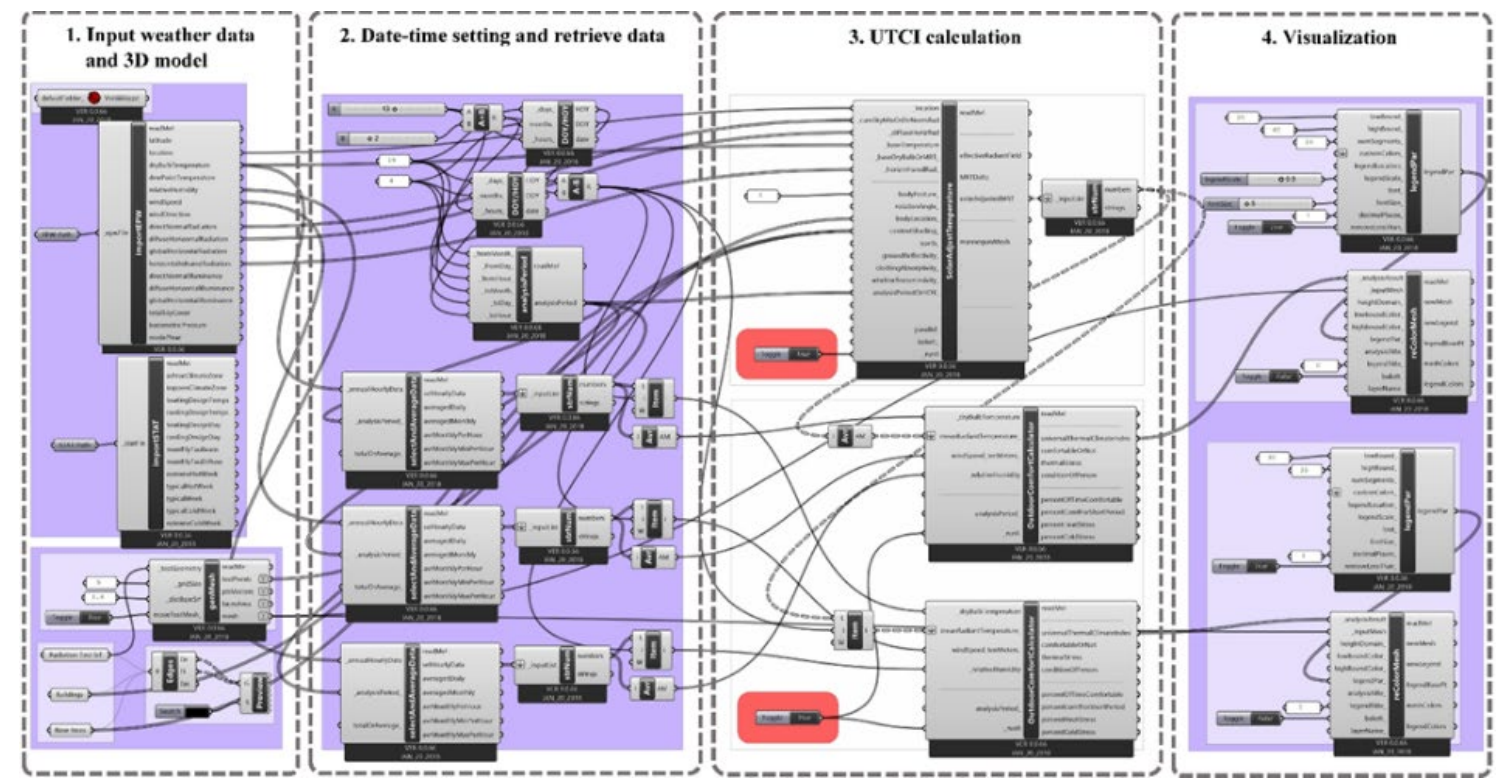

Figure 5: UTCI calculation script and data visualization process (Rhinoceros and Grasshopper).

\subsection{Simulation Scenarios}

To study the effects of various shade types, four different scenarios vary by shade type, presented in Table 2 .

Table 2: Details of simulation scenarios.

\begin{tabular}{|c|c|c|c|c|c|}
\hline & & Base-case & Case-1 & Case-2 & Case-3 \\
\hline Scenari & & & & & \\
\hline Shading area & $\mathrm{m}^{2}$ & - & 600 & 1,047 & 1,425 \\
\hline increase & $\%$ & - & 1.92 & 3.36 & 4.57 \\
\hline Details & & Existing are & Increased tree shading & $\begin{array}{l}\text { Increased cover-way } \\
\text { shading }\end{array}$ & $\begin{array}{l}\text { Increased trees and } \\
\text { cover-way shading }\end{array}$ \\
\hline
\end{tabular}

\section{RESULTS}

This section consists of two parts: UTCI simulation results and then results from the analysis. From the processing there are two types of results, for the three periods (9:00-11:00, 13:00-15:00, 16:00-18:00) and all four simulation cases, namely heat maps and numeric dataset (the unit of these results is ${ }^{\circ} \mathrm{C}$ ) are presented. Therefore, it is necessary to bring both results together for a complete analysis, as in Table 3. 
Table 3: UTCI results from scenarios simulation.

\begin{tabular}{|c|c|c|c|c|}
\hline Time & Base-case & Case-1 & Case-2 & Case-3 \\
\hline $\begin{array}{l}9: 00- \\
11: 00\end{array}$ & 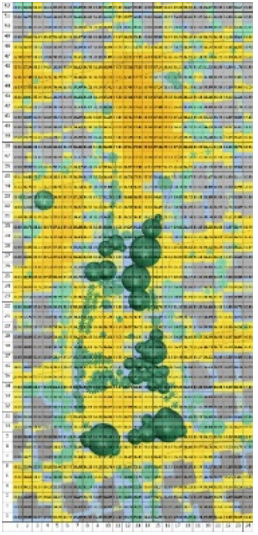 & 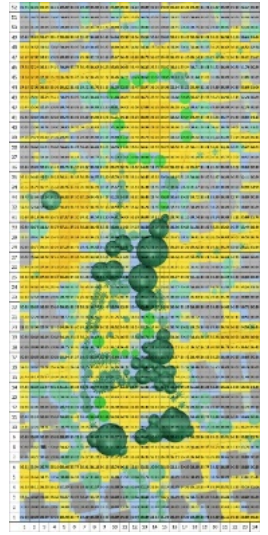 & 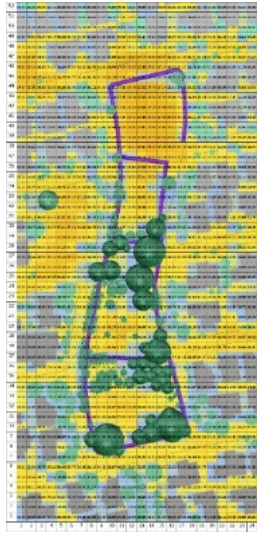 & 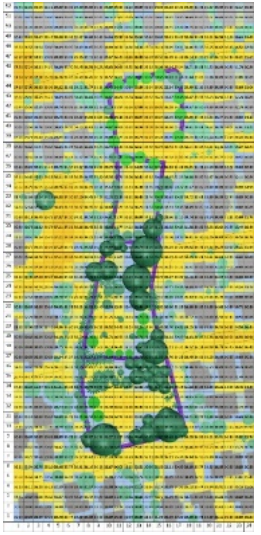 \\
\hline $13: 00-$ & 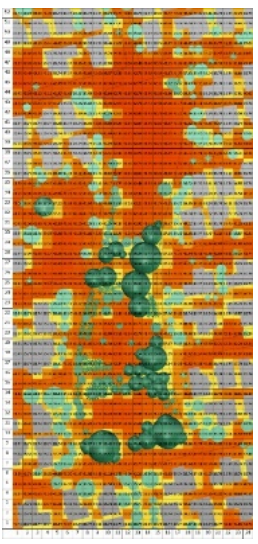 & 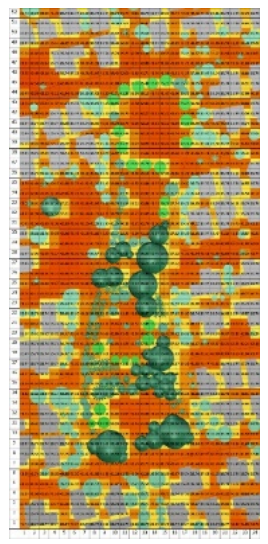 & 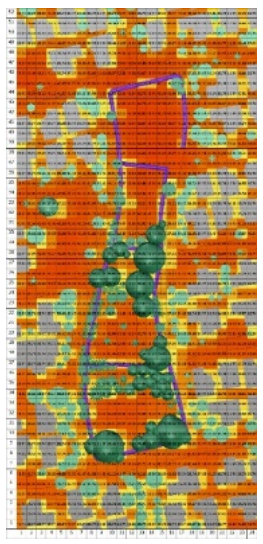 & 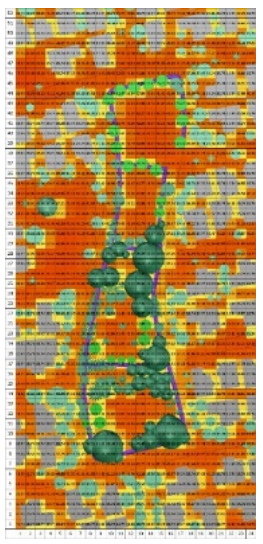 \\
\hline $18: 00$ & 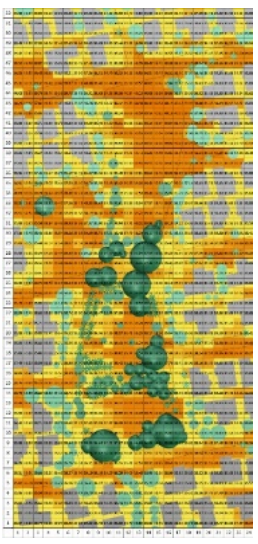 & 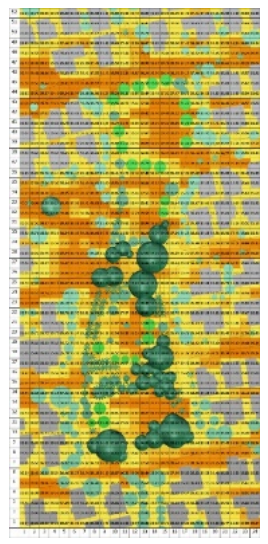 & 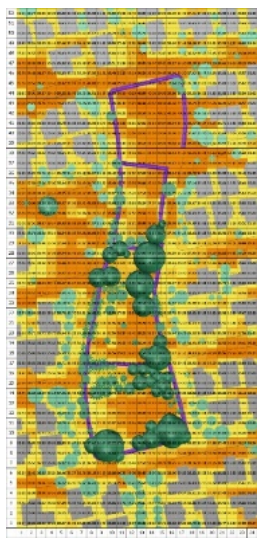 & 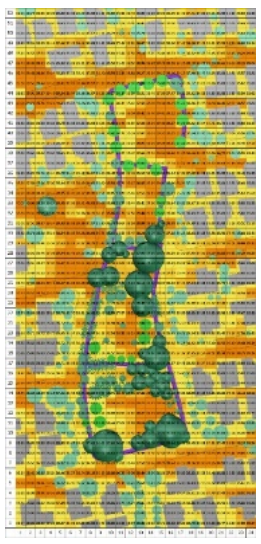 \\
\hline $\begin{array}{l}\text { Legend } \\
\left({ }^{\circ} \mathrm{C}\right)\end{array}$ & 26 & & & 45 \\
\hline
\end{tabular}

From the results presented above, the efficiency of the shade type in each case can be analyzed from the ratio of the $\triangle \mathrm{UTCI}$ to the increase in the color space $\left({ }^{\circ} \mathrm{C} / \mathrm{m}^{2}\right)$, with the details of the three cases as follows:

1. Case-1: An increase of $598.71 \mathrm{~m}^{2}$ in tree shade has a result in the ratio of $\triangle \mathrm{UTCI}$ per increased shade area between 9:00-11:00, 13:00-15:00 and $16: 00-18: 00$ as $4.68 \times 10^{-4}, 4.68 \times 10^{-4}$, and $3.34 \times 10^{-4}{ }^{\circ} \mathrm{C} / \mathrm{m}^{2}$, respectively. When considering the whole day, the ratio of $\triangle \mathrm{UTCI}$ per increased shade area is $4.17 \times 10^{-4}{ }^{\circ} \mathrm{C} / \mathrm{m}^{2}$.
2. Case-2: Increase of $1,047.22 \mathrm{~m}^{2}$ in cover-way shading has a result in the ratio of $\triangle \mathrm{UTCI}$ per increased shade area between 9:00-11:00, 13:00-15:00 and 16:00-18:00 as $1.05 \times 10^{-4}$, $0.95 \times 10^{-4}$ and $0.48 \times 10^{-4} \mathrm{C} / \mathrm{m}^{2}$, respectively. When considering the whole day, the ratio of $\triangle$ UTCI per increased shade area is $0.85 \times 10^{-}$ ${ }^{4} \mathrm{C} / \mathrm{m}^{2}$.

3. Case- 3 : Increase of $1,424.79 \mathrm{~m}^{2}$ in tree shade and cover-way shading has a result in the ratio of $\triangle \mathrm{UTCI}$ per increased shade area between 
9:00-11:00, 13:00-15:00 and 16:00-18:00 as $2.31 \times 10-4,2.24 \times 10^{-4}$ and $1.61 \times 10^{-4}{ }^{\circ} \mathrm{C} / \mathrm{m}^{2}$, respectively. When considering the whole day, the ratio of $\triangle \mathrm{UTCI}$ per increased shade area is $2.03 \times 10^{-4}{ }^{\circ} \mathrm{C} / \mathrm{m}^{2}$.

When arranging the efficiency of the shade types over a whole day for each case by descending order, the results are as follows: Case-1, Case-3, and Case2.

A summary of the results of the UTCI simulation analysis is a decrease in the UTCI that is linked to an increase in the shaded area. The greater the shaded area increase, the more that the UTCI will be reduced. A summary of the results of the shade type efficiency is an increase in the tree shade that can cause a decrease in the UTCI. The efficiency of the shade types in descending order are as follows: tree shade was the most efficient, then the tree and coverway shading, and the cover-way shading alone was the least efficient, which is in the same direction as the others outdoor thermal comfort indicator (Srivanit \& Jareemit, 2020). An increase in the shaded area can reduce the occurrence of heat stress in public space and having a suitable area of shade will encourage more use of the public space.

From the results above, the suggestions for shade area design in urban housing estate development are as follows: to prevent the occurrence of heat stress, they should be designed to have appropriate and sufficient shaded areas with covering for the outdoor public space. The efficiency of trees for shade means the design of outdoor public space should have more trees for shade than other shade types.

\section{CONCLUSION}

From the need for great outdoor spaces to support the living environment of residents who live in the large-scale real estate project, the UTCI index is adopted to measure the outdoor thermal comfort which reflects the quality of the space design. By using the computer programming -Rhinoceros and Grasshopper, its features in modeling techniques for developing a model and create an environmental impact evaluation suite. The results present the significance and acceptable of adding shaded areas via large trees that can result in thermal reduction and humidity increase, comparing with the shading from mand-made cover way as mentioned in the research of Hsieh et al. (2018) that increasing of the tree shadows can reduce the area heat and also affect to decrease the building energy usage. The trees provided efficient shade, but they do not obstruct air circulation and supply the moisture to the surrounding air, which benefits the comfort condition and induces highly area appreciation from the residents (Abdi et al., 2020).
The study also found that the study processes, tools, and techniques can be an example to design and create shading areas for open space in the housing estate, there were able to conclude alternatives that are consistent with the principles and gain useful information for decision making very well. The results of the study also provide evidence to support this method that simulations by Rhinoceros and Grasshopper programs in the design of environment (Nakano, 2015; Rakha, 2015), for selecting the appropriate model for the further development of the project.

\section{REFERENCES}

[1] Abdi, B., Hami, A., \& Zarehaghi, D. (2020). Impact of small-scale tree planting patterns on outdoor cooling and thermal comfort. Sustainable Cities and Society, 56, 102085.

[2] Blazejczyk, K., Epstein, Y., Jendritzky, G., Staiger, H., \& Tinz, B. (2011). Comparison of UTCI to selected thermal indices. International journal of biometeorology, 56, 515-535.

[3] Bröde, P., Krüger, E., \& Fiala, D. (2013). UTCI: Validation and practical application to the assessment of urban outdoor thermal comfort. Geographia Polonica, 86, 11-20.

[4] Bröde, P., Krüger, E., \& Rossi, F. (2011). Assessment of urban outdoor thermal comfort by the Universal Thermal Climate Index UTCI. Paper presented at the 14th International Conference on Environmental Ergonomics, Greece

[5] Choruengwiwat, J., Pongsuwan, S., Kieatkongmanee, N., Rinchumphu, D., Srivanit, M., \& Yang, C. Y. (2019). The eco-efficiency model for outdoor environmental design of the mixed-use real estate development in Bangkok, Thailand. Journal of Architectural/Planning Research and Studies (JARS), 16(1), 35-43.

[6] Fahmy, M., \& Elwy, I. (2016). Visual and Thermal Comfort Optimization for Arid Urban Spaces using Parametric Techniques on the Scale of Compactness Degree. Paper presented at the 36th International Conference on Passive and Low Energy Architecture. Cities, Buildings, People: Towards Regenerative Environments.

[7] Havenith, G., Fiala, D., Blazejczyk, K., Richards, M., Bröde, P., Holmér, I., Rintamaki, H., Benshabat, Y., \& Jendritzky, G. (2011). The UTCI-clothing model. International journal of biometeorology, 56, 461-470.

[8] Hsieh, C.-M., Li, J.-J., Zhang, L., \& 
Schwegler, B. (2018). Effects of tree shading and transpiration on building cooling energy use. Energy and Buildings, 159, 382-397.

[9] Jitkhajornwanich, K. (2007). Thermal comfort and adaptability to living for local people. (pp. 230): Silpakorn University Research and Development Institute.

[10] Li, W., Ouyang, Z., Zhou, W., \& Chen, Q. (2011). Effects of spatial resolution of remotely sensed data on estimating urban impervious surfaces. Journal of Environmental Sciences, 23(8), 1375-1383.

[11] Milosevic, D., Savic, S., \& Bajšanski, I. (2017). Applications of automatic algorithms for improvement of outdoor thermal comfort in cities. Procedia Engineering, 198, 187-192.

[12] Naboni, E., Meloni, M., Coccolo, S., Cucchi, F., Macrelli, G., Kaempf, J., et al. (2017). The integration of outdoor thermal simulation tools in architectural design (Vol. 2, pp. 2100-2107).

[13] Nakano, A., Bueno, B., Norford, L., \& Reinhart, C. F. (2015). Urban weather generator user interface development : towards a usable tool for integrating urban heat island effect within urban design process. Paper presented at the 9th International Conference on Urban Climate jointly with 12th Symposium on the Urban Environment.

[14] Nugroho, A. M., Citraningrum, A., Iyati, W., \& Ahmad, M. H. (2020). Courtyard as Tropical Hot Humid Passive Design Strategy: Case Study of Indonesian Contemporary Houses in Surabaya Indonesia. Journal of Design and Built Environment, 20(2), 1-12.

[15] Peccolo, C. (1962). The effect of thermal environment on learning, a pilot study. Iowa University, Iowa City: Iowa Center for Research in School Administration.

[16] Rakha, T., \& Reinhart, C. (2012). Generative urban modeling: a design work flow for walkability-optimized cities. Paper presented at the 5th National Conference of IBPSA-USA.

[17] Reinhart, C., Dogan, T., Jakubiec, J., Rakha, T., \& Sang, A. (2013). UMI - An urban simulation environment for building energy use, daylighting and walkability. Paper presented at the 13th Conference of International Building Performance Simulation Association.

[18] Roudsari, M. S., \& Pak, M. (2013). Ladybug: A parametric environmental plugin for grasshopper to help designers create an environmentally-conscious design. Proceedings of BS 2013: 13th Conference of the International Building Performance Simulation Association, 3128-3135.

[19] Silva, T. J. V., \& Hirashima, S. Q. S. (2021). Predicting urban thermal comfort from calibrated UTCI assessment scale - A case study in Belo Horizonte city, southeastern Brazil. Urban Climate, 36, 100652.

[20] Srivanit, M., \& Jareemit, D. (2020). Modeling the influences of layouts of residential townhouses and tree-planting patterns on outdoor thermal comfort in Bangkok suburb. Journal of Building Engineering, 30, 101262.

[21] Thongsri, K., Sethabutr, A., \& Jindawanik, T. (2006). The study of the effect of airflow on users of outdoor areas: a case study of Siriraj Hospital. Academic journal Faculty of Architecture, Chulalongkorn University, 2, 49-78.

[22] Wang, B., \& Yi, Y. K. (2021). Developing an adapted UTCI (Universal Thermal Climate Index) for the elderly population in China's severe cold climate region. Sustainable Cities and Society, 69, 102813.

[23] Wang, W. W., Zhu, L. Z., \& Wang, R. C. (2004). An analysis on spatial variation of urban human thermal comfort in Hangzhou, China. Journal of Environmental Sciences, 16(2), 332-338. 